\title{
Evolução da notificação de violência contra mulher no município de São Paulo, 2008-2015
}

\section{Notification of violence against women in the city of São Paulo, 2008-2015}

Kelly Roberta Estrela Marinho Neto', Vania Reis Girianelli² (D)

'Secretaria Municipal de São Gonçalo - Rio de Janeiro (RJ), Brasil.

${ }^{2}$ Departamento de Direitos Humanos, Saúde e Diversidade Cultural, Escola Nacional de Saúde Pública Sérgio Arouca (ENSP),

Fundação Oswaldo Cruz (Fiocruz) - Rio de Janeiro (RJ), Brasil.

Como citar: Marinho Neto KRE, Girianelli VR. Evolução da notificação de violência contra mulher no município de São Paulo, 2008-2015. Cad Saúde Colet, 2020;28(4):488-499. https://doi.org/10.1590/1414-462X202028040404

\section{Resumo}

Introdução: A violência demanda assistência em saúde devido às lesões físicas e psíquicas que ocasiona e consequentemente compromete a qualidade de vida do indivíduo. A notificação é uma dimensão da linha de cuidado, que também possibilita dar visibilidade ao problema da violência e subsidia as políticas públicas. Objetivo: Descrever as características da violência contra as mulheres notificadas no município de São Paulo, 2008-2015. Método: Estudo ecológico descritivo sobre os casos de violência interpessoal contra mulheres de 20 a 59 anos registrados na Prefeitura de São Paulo, sendo avaliada a tendência temporal por regressão linear simples e as características dos envolvidos e da violência. Resultados: 43.256 casos foram notificados, evidenciando aumento no período $(\beta=0,001 ; p=0,006)$; a violência física foi predominante (81,3\%) entre mulheres de 20 a 29 anos (37,6\%). O agressor era do sexo masculino $(47,7 \%)$ e conhecido $(62,5 \%)$, com ocorrência na residência da vítima (31,6\%); as partes do corpo mais atingidas foram a cabeça $(31,7 \%)$ e os membros $(21,4 \%)$, ocasionando principalmente traumas $(60 \%)$. Conclusão: As notificações de violência contra a mulher têm aumentado no município de São Paulo, mas a violência física, que tem maior visibilidade, ainda se sobressai, sugerindo a existência de subnotificação. Palavras-chave: Violência contra a mulher; Direitos Humanos; Saúde Pública; notificação compulsória; Sistema de Informações de Agravos de Notificação (SINAN).

\begin{abstract}
Background: Violence demands health care due to the physical and psychological injuries it causes and consequently compromises the individual's quality of life. Notification is a dimension of the care line, which also enables to give visibility to the problem of violence and subsidizes public policies. Objective: To describe the characteristics of violence against women reported in the city of São Paulo, 2008-2015. Method: a descriptive ecological study on the cases of interpersonal violence against women aged 20 to 59 years registered in the city of São Paulo, evaluating the temporal trend by simple linear regression and the characteristics of those involved and violence. Results: We identified 43,256 reported cases, evidencing an increase in the period $(\beta=0.001 ; p=0.006)$; with physical aggression as predominant $(81.3 \%)$ and among women aged $20-29$ years old (37.6\%). The aggressor was male (47.7\%) and known (62.5\%), occurring at victim's home (31.6\%); the head (31.7\%) and limbs (21.4\%) were the most affected parts of the body causing mainly trauma (60.0\%). Conclusion: Reports of violence against women have increased in the city of São Paulo, but physical violence, which has greater visibility, still stands out, suggesting the existence of underreporting.
\end{abstract}

Keywords: Violence against women; Human rights; Public health; compulsory notification; Health Information System.

Trabalho realizado na Escola Nacional de Saúde Pública Sérgio Arouca (ENSP), Fundação Oswaldo Cruz (Fiocruz) - Rio de Janeiro (RJ), Brasil.

Correspondência: Vania Reis Girianelli. E-mail: vaniagirianelli@yahoo.com.br

Fonte de financiamento: nenhuma.

Conflito de interesses: nada a declarar.

Recebido em: Ago. 28, 2018. Aceito em: Dez. 13, 2019

Este é um artigo publicado em acesso aberto (Open Access) sob a licença Creative Commons Attribution, que permite uso, distribuição e reprodução em qualquer meio, sem restrições desde que o trabalho original seja corretamente citado. 


\section{INTRODUÇÃO}

A violência é influenciada por fatores sociais, culturais e econômicos, com grande impacto na sociedade, mas por muito tempo foi abordada apenas pelo setor da segurança pública. Na década de 1990, em virtude do aumento da morbimortalidade por violência na América Latina, a Organização Pan-Americana (OPAS) incluiu o tema na agenda da saúde ${ }^{1}$. Posteriormente, a Assembleia Mundial de Saúde, realizada em 1996, reconhece o aumento da violência intencional no mundo, que afeta pessoas de ambos os sexos e de todas as idades, em particular mulheres e crianças, declarando ser um importante problema de saúde pública. Como desdobramento foi organizado o primeiro relatório mundial sobre violência e saúde, com contribuição de 160 especialistas do mundo inteiro trazendo recomendações para o enfrentamento do problema².

O século XX foi marcado por movimentos sociais em busca dos direitos fundamentais que contribuíram para a publicação da Declaração Universal dos Direitos Humanos ${ }^{3}$. Esse documento menciona a igualdade de direitos entre homens e mulheres, mas não especifica a violação dos direitos das mulheres. Apenas a partir da década de 1960, em função da pressão dos movimentos feministas de diversos países, um conjunto de Convenções Internacionais, ratificadas pelo Brasil, inclui a categoria "mulher" nos diversos temas abordados, culminando na Convenção Interamericana para Prevenir, Punir e Erradicar a Violência contra a Mulher, conhecida como Convenção de Belém do Pará4.

A violência contra a mulher no Brasil passou a ter maior visibilidade com a Lei $n^{\circ} 11.340^{5}$, considerando qualquer ação ou omissão que leve à morte, lesão física, sexual, psicológica e dano moral ou patrimonial. Essa lei foi instituída após o país ser condenado internacionalmente em 2001 por negligência às denúncias referentes às diversas agressões sofridas por Maria da Penha pelo seu marido, que a deixou paraplégica, sendo o primeiro caso de aplicação da Convenção de Belém do Pará. A lei promulgada anteriormente ${ }^{6}$ tipificava e aumentava a pena nos casos de violência doméstica e familiar, mas era restrita a danos físicos e mentais.

Em 2003, também foi implantada a notificação de violência contra mulher ${ }^{7}$. Na prática, entretanto, apenas os serviços de referência à assistência da mulher, definidos pelas secretarias municipais e estaduais de saúde, notificavam. Posteriormente, a notificação de violência contra mulher foi integrada à ficha de notificação de violência autoprovocada e interpessoal, e inserida de forma gradual no Sistema de Informação de Agravos de Notificação (Sinan), conforme a adesão dos estados e municípios ${ }^{8}$. Somente em 2011, entretanto, as violências passaram a integrar a lista nacional de doenças e agravos de notificação compulsória ${ }^{9}$. A Organização Mundial da Saúde ${ }^{10}$ estima que 35\% das mulheres no mundo já vivenciaram violência física ou sexual e $38 \%$ dos assassinatos são cometidos por parceiros íntimos. Dados do Brasil do início do século, que contribuíram para essa estimativa, revelaram que $46,4 \%$ das mulheres de 15 a 49 anos residentes na cidade de São Paulo informaram terem sido vítimas de violência por parceiro íntimo ${ }^{11}$.

A violência demanda assistência em saúde, devido às lesões físicas e psíquicas que ocasiona, e consequentemente compromete a qualidade de vida do indivíduo. A notificação é uma dimensão da linha de cuidado, que também possibilita dar visibilidade ao problema da violência, subsidiando o planejamento, organização dos serviços e as políticas públicas ${ }^{12}$. Estudos recentes sobre notificação de violência contra mulheres foram realizados no Distrito Federal ${ }^{13}$, Minas Gerais ${ }^{14}$ e Santa Catarina ${ }^{15}$. O município de São Paulo, entretanto, que é a cidade brasileira mais populosa e mais influente no cenário mundial, ainda não foi apreciado.

O objetivo deste estudo é analisar o comportamento temporal das notificações de violência contra a mulher e descrever as características dos casos notificados no município de São Paulo, no período entre 2008 e 2015, de forma a contribuir para o debate de ações para o enfrentamento da violência. 


\section{MÉTODO}

Trata-se de estudo ecológico de série temporal sobre as notificações de violência contra mulheres no município de São Paulo. Foram elegíveis as mulheres com idade entre 20 e 59 anos residentes no município e vítimas de violência interpessoal no período entre 2008 e 2015.

O município de São Paulo é a capital do estado de São Paulo, localizado na região Sudeste do país. A população está estimada em 12.106.920, sendo a cidade brasileira mais populosa, abrigando cerca de $6 \%$ dos habitantes do país. As mulheres representam $53 \%$ da população do município, e aquelas com idade entre 20 e 59 anos correspondem a cerca de $60 \%$ do total da população feminina. O município possui o $10^{\circ}$ maior Produto Interno Bruto (PIB) do mundo, representando isoladamente $10,7 \%$ do PIB de todo o Brasil. Apresenta o segundo maior índice de desenvolvimento humano - IDH $(0,805)$ - e alto percentual de escolaridade na população de 6 a 14 anos $(96 \%)^{16}$.

Neste estudo as variáveis analisadas relacionadas à vítima foram: características sociodemográficas (idade, raça/cor, escolaridade), presença de deficiência e gravidez. A idade foi categorizada em intervalo de dez anos. Quanto ao provável agressor foram descritos o sexo e sua relação com a vítima (familiar, patrão, outros conhecidos, assaltante, outros desconhecidos). As variáveis relacionadas às características da violência foram: tipo da violência (física, sexual, psicológica, negligência), meio ou instrumento utilizado (força corporal, arma etc.), frequência (uma, duas a cinco, seis ou mais), local da ocorrência (residência, via pública, outro), partes do corpo mais agredidas (cabeça, pescoço, membros etc.), formas da agressão (ferimento, fratura, trauma etc.) e evolução (alta, óbito, transferência, acompanhamento).

Os dados foram extraídos do site da prefeitura ${ }^{17}$, a partir do Sistema de Informação e Vigilância de Violências e Acidentes (SIVVA) da Coordenação em Vigilância em Saúde do Município de São Paulo (Covisa), que são de acesso público e sem identificação individual. O município de São Paulo manteve um sistema próprio com disponibilização dos dados de violência para o período de 2008 ao primeiro semestre de 2015, e só posteriormente passou a utilizar o Sinan, mas com disponibilização dos dados a partir do último trimestre de 2018.

Calculou-se o percentual de cada categoria das variáveis estudadas. A tendência temporal foi avaliada por regressão linear simples, tendo como variável independente o ano de notificação e como variável dependente o número de notificações ou a proporção de cada categoria das variáveis analisadas. O aumento ou declínio do quantitativo ou da proporção das notificações no período foram avaliados com base no coeficiente de regressão $(\beta)$ e respectiva significância estatística ( $p \leq 0,05$ ). Os dados foram armazenados no programa Excel, versão 2013, e analisados no programa estatístico R, versão 3.4.3.

\section{RESULTADOS}

Entre os anos de 2008 e 2015 foram registradas 38.453 notificações de violência contra a mulher, no município de São Paulo (SP). Houve um aumento estatisticamente significativo das notificações até 2014 ( $\beta=682,0 ; p=0,010$ ). Não foi considerado o ano de 2015 porque os dados são parciais. A maioria das notificações foi de violência física $(91,5 \%)$, seguida de violência psicológica $(15,5 \%)$, ambas com tendência estável no período $(p \geq 0,207)$. Houve, entretanto, aumento da proporção das notificações de violência sexual e múltiplas violências $(\beta=0,410$, $p=0,029$ e $\beta=1,167, p=0,049$; respectivamente) (Tabela 1).

A Tabela 2 apresenta as características das vítimas. Houve predomínio das notificações das mulheres mais jovens (20 a 29 anos) e com mais de sete anos de estudo, 42,3\% e 22,7\%, respectivamente, embora com aumento na proporção das notificações das mais idosas ( $\geq 50$ anos) $(\beta=0,271, p=0,012)$. As notificações entre brancas $(26,9 \%)$ e não brancas $(28,8 \%)$ se aproximaram, mas com aumento estatisticamente significativo da proporção de mulheres brancas no período $(\beta=0,578, p=0,030)$. Já em relação à escolaridade houve aumento na proporção de notificações das mulheres com mais de sete anos de estudo, principalmente das com doze anos ou mais $(\beta=1,012, p<0,001)$. Verificou-se, contudo, alto percentual de dados ignorados, em particular para escolaridade (61\%) e raça/cor $(44,2 \%)$, mas com decréscimo no 


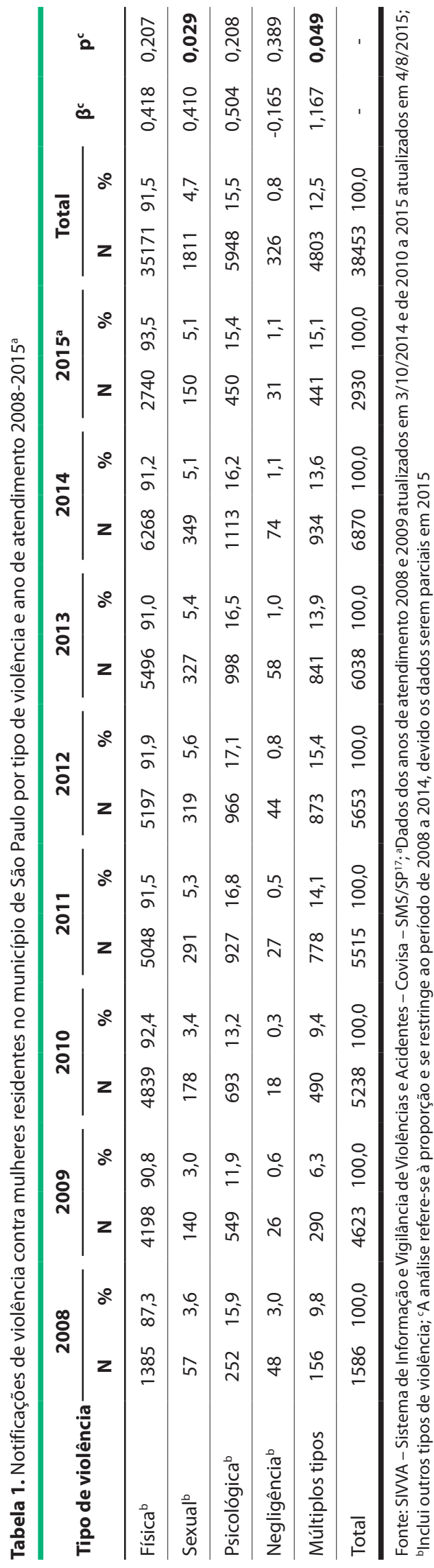




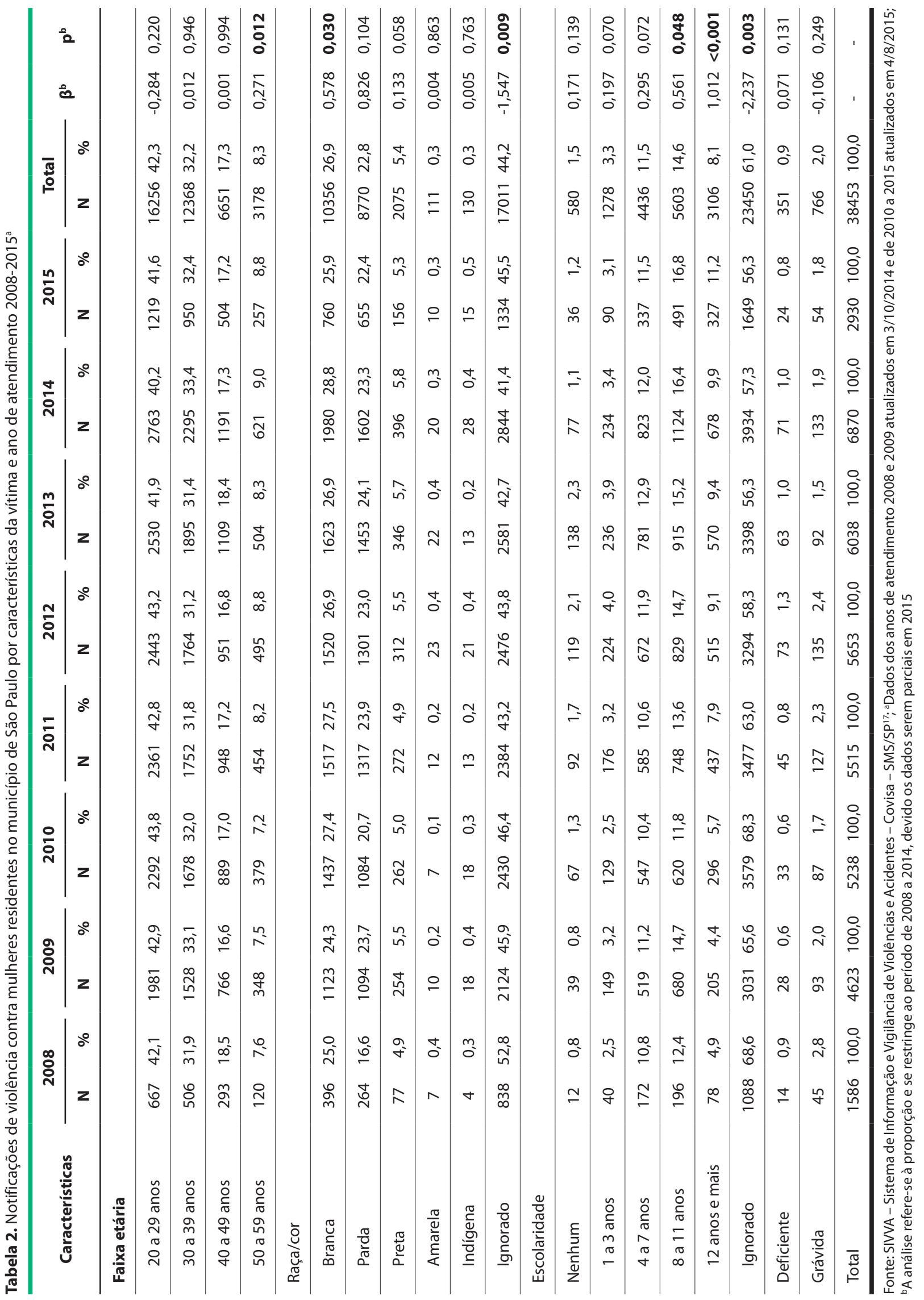


período ( $\beta=-2,237, p=0,003$ e $\beta=-1,547, p=0,009$; respectivamente). Destaca-se a presença de notificação de violência em gestantes ( $2 \%$ ) e deficientes $(0,9 \%)$.

A maioria dos agressores era do sexo masculino $(53,7 \%)$ e conhecido $(70,2 \%)$, principalmente familiar (53,6\%). As informações sobre os prováveis agressores também apresentaram alto percentual de ignorado destas variáveis $34,6 \%$ e $20,1 \%$, respectivamente (Tabela 3). Ressalta-se que $61,1 \%$ das notificações de violência sexual foram cometidas por conhecidos, e destes, $76,6 \%$ por familiares.

A Tabela 4 apresenta as características das agressões notificadas. A maioria da violência ocorreu na residência da vítima $(35,6 \%)$ e não foi a primeira notificação (24,4\%), porém com alto percentual de informação ignorada destas variáveis ( $72,9 \%$ e $59,1 \%$, respectivamente). Ademais, a ausência de informação sobre o local da agressão tem aumentado $(\beta=2,699, p=0,002)$.

Dentre as notificações de agressão física (Tabela 4), o uso da força corporal predominou $(45,6 \%)$, embora os meios não especificados tenham sido expressivos (47,7\%). A cabeça foi a parte do corpo mais agredida $(37,1 \%)$, seguida dos membros $(21,4 \%)$, mas com queda no período ( $\beta=-1,386, p=0,006$ e $\beta=-1,143, p=0,001$; respectivamente). Ressalta a agressão em múltiplas partes $(14,9 \%)$ e a ausência de informação $(20,6 \%)$, que tem aumentado $(\beta=2,743, p=0,003)$.

Em relação à evolução, $70,9 \%$ das notificações tinham registro de alta. Não obstante, $14 \%$ das notificações mantinham o registro de em acompanhamento de saúde, permanecendo essa proporção ao longo do período $(\beta=-0,262 ; p=0,587$ ) (Tabela 5 ).

\section{DISCUSSÃO}

As notificações de violência contra a mulher têm aumentado no município de São Paulo ( $\beta=682,0 ; p=0,010$ ), mesmo antes de 2011, quando não havia obrigatoriedade da notificação, mas a violência física, que tem maior visibilidade, ainda corresponde à maioria das notificações $(91,5 \%)$, sugerindo a existência de subnotificação. Observou-se, contudo, um aumento da proporção das notificações por múltiplas violências $(\beta=1,167, p=0,049)$ e sexual $(\beta=0,410, p=0,029)$. Espera-se, entretanto, uma redução das notificações de múltiplas violências, bem como da violência psicológica, devido à recomendação de assinalar apenas a violência considerada principal, embora ainda não haja restrição para digitação de diversos tipos de violência no sistema. Estudos realizados em algumas cidades do país também têm identificado maior proporção de notificação de violência física ${ }^{13,14}$. Já quando as usuárias dos serviços de saúde são entrevistadas, a violência psicológica é a mais prevalente ${ }^{18-20}$. Além disso, a maioria das mulheres informou que procuraria apenas a delegacia por desconhecerem a existência do atendimento nos serviços de saúde ${ }^{19}$. Em contrapartida, os profissionais de saúde ainda veem a notificação como sinônimo de denúncia ${ }^{21}$, ou seja, como uma questão apenas de segurança pública, o que pode inibir o registro das violências. Esses estudos corroboram a ocorrência de subnotificação e sinalizam a necessidade de maior investimento no treinamento dos profissionais de saúde para identificar mulheres vítimas de violência e consequentemente minimizar oportunidades perdidas de assistência e prevenção.

A maioria das notificações (42,3\%) ocorreu nas mulheres mais jovens (20 a 29 anos), embora represente menos de $30 \%$ da proporção da população feminina do município de São Paulo entre 20 e $59 \operatorname{anos}^{16}$. Esta análise, no entanto, está prejudicada devido à existência de múltiplos episódios de violência, podendo ter mais de uma notificação por pessoa no mesmo ano. Adicionalmente, verificou-se aumento na proporção das notificações das mulheres mais idosas ( $\geq 50$ anos) no período $(\beta=0,271, p=0,012$ ). A descrição das demais características das vítimas também ficou comprometida devido ao alto percentual de incompletude das variáveis sociais. Nos demais sistemas de informação do município de São Paulo, no entanto, a completitude da variável raça/cor tem variado de 15,7\% (Sistema de Informação de Câncer de Colo de Útero - Siscolo) a 99,9\% (Sistema de Informação de Nascidos Vivos - Sinasc), sendo mais baixa nos sistemas com implantação mais recente ${ }^{22}$. As demais variáveis, portanto, devem apresentar um padrão semelhante, melhorando a qualidade do preenchimento com a experiência. Não obstante, como a notificação tende a ser preenchida principalmente nas 


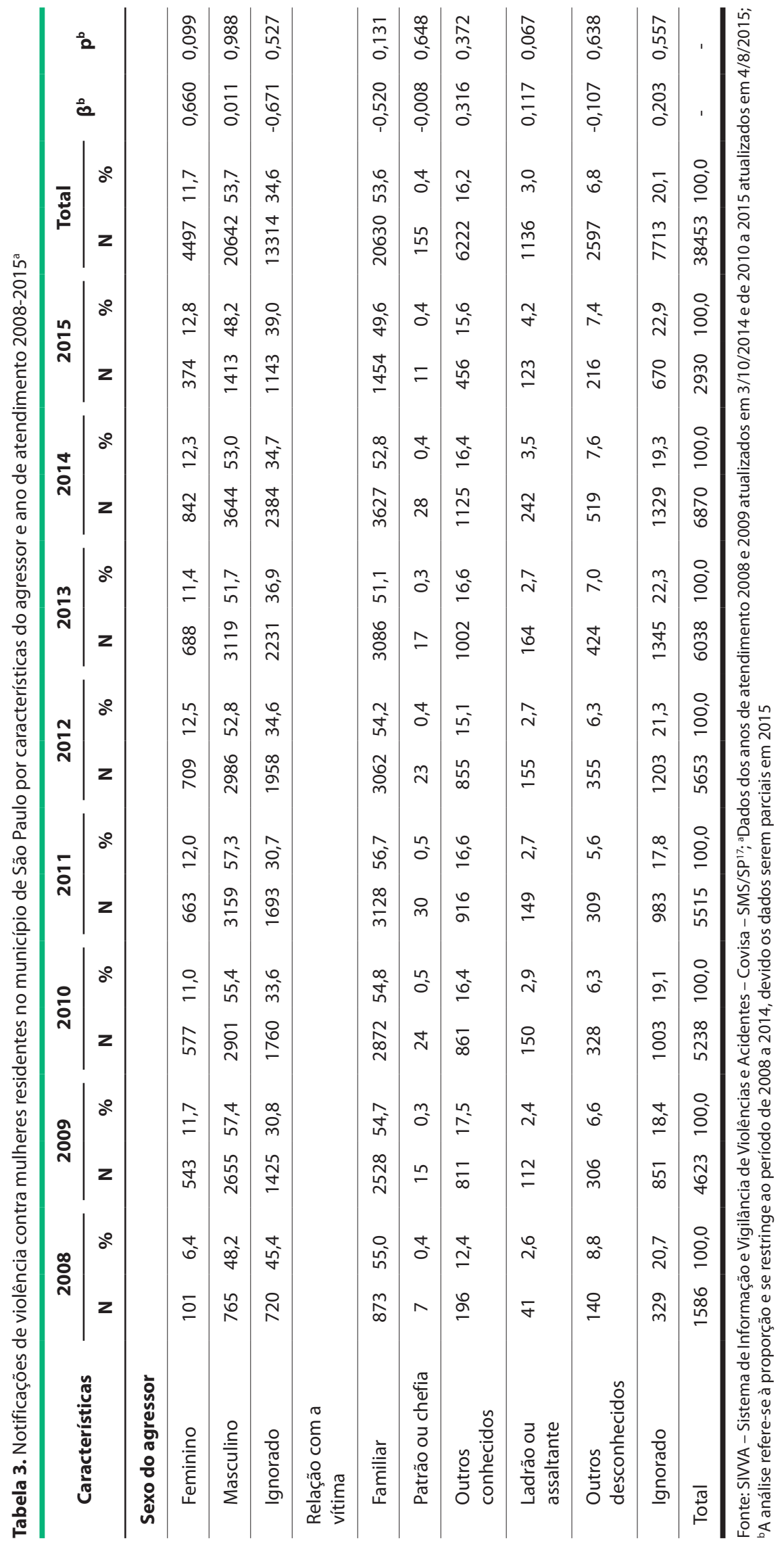




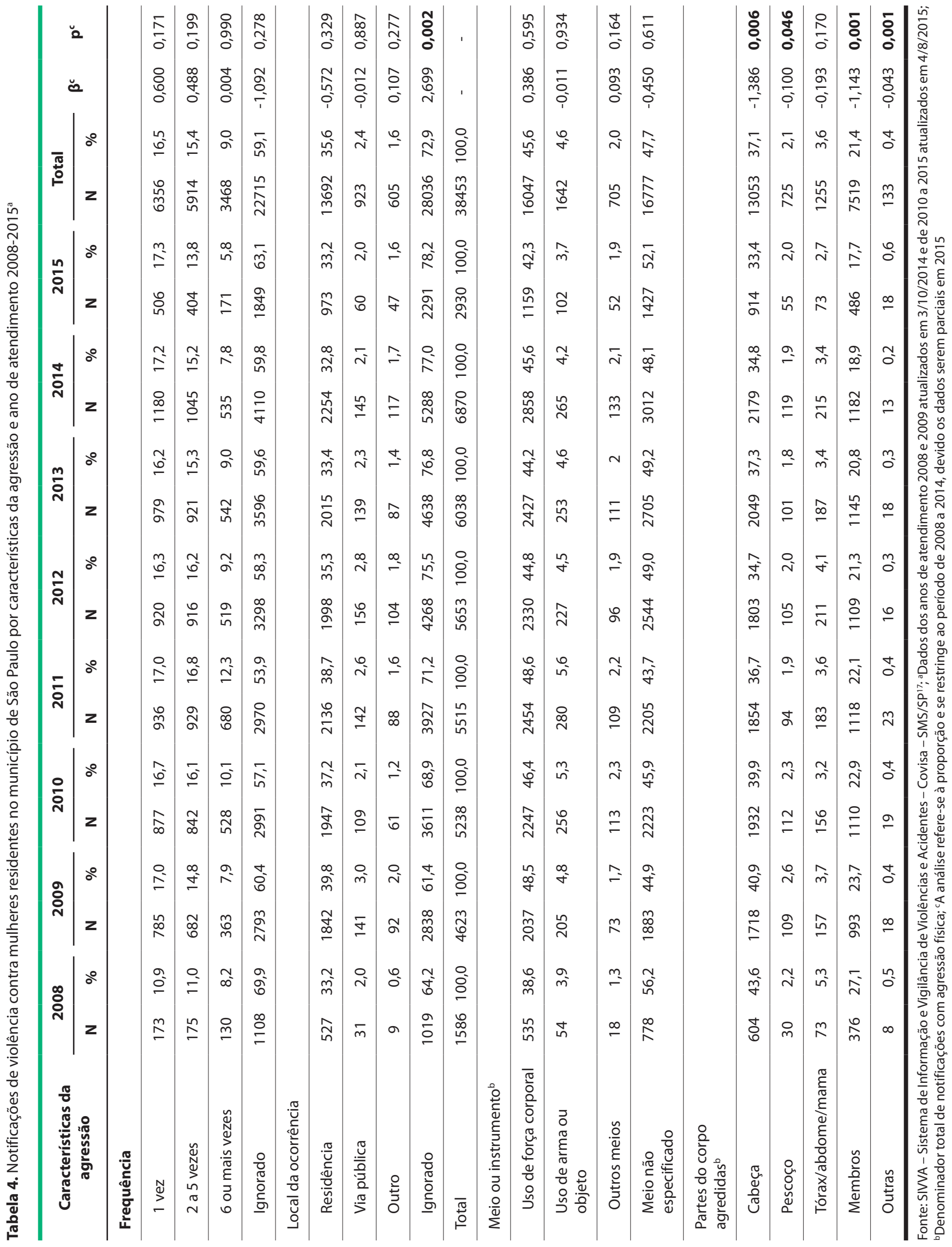




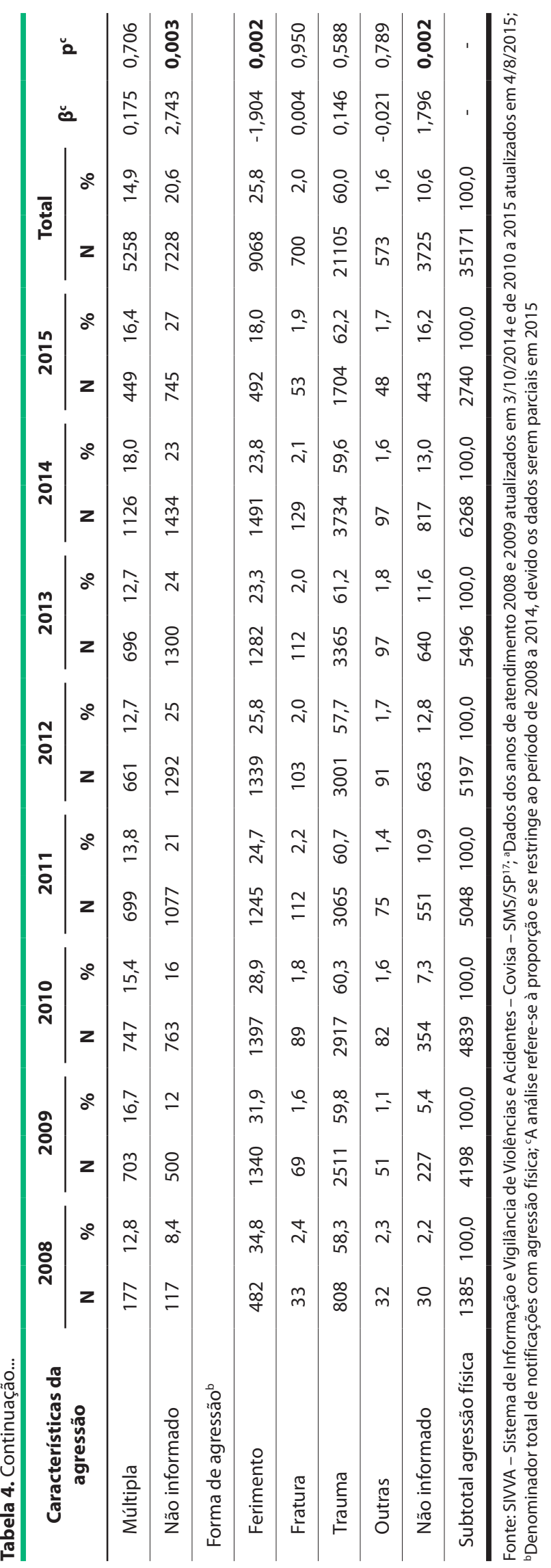




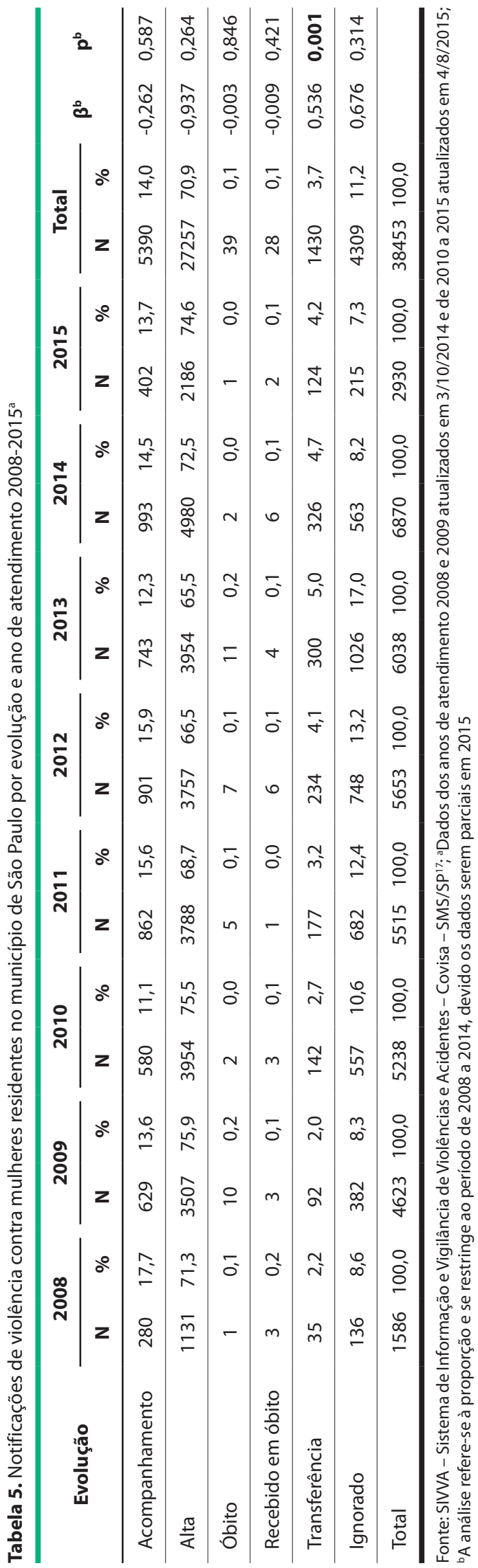


instituições públicas, espera-se um perfil semelhante às usuárias desses serviços, em particular para violência doméstica, que independe de classe social ou nível educacional ${ }^{23}$.

Em consonância com os demais estudos, as notificações têm mostrado que a maioria da violência contra mulher é doméstica, em que o agressor tem proximidade com a vítima ${ }^{24,25}$. A despeito do alto percentual de informação ignorada, que pode estar relacionada ao medo de identificar o agressor por receio de represálias, nas notificações de violência sexual, em particular, verificou-se que $61,1 \%$ foram praticadas por conhecidos, principalmente familiares $(76,6 \%)$, situação similar foi observada em estudo realizado em Santa Catarina ${ }^{15}$. Adicionalmente, os episódios tendem a ser repetitivos e progressivos e podem evoluir para assassinato, mesmo nos casos de violência psicológica ${ }^{26}$.

$\mathrm{Na}$ violência física a cabeça e a face foram as mais atingidas, seguidas dos membros, concordando com o observado em outros estudos ${ }^{13,27,28}$. A parte do corpo preferida dos agressores é a face, e quando os membros são alcançados, geralmente, é para protegê-la ${ }^{27}$. A agressão é direcionada a uma área que tem referência simbólica, de forma a afetar a vaidade da mulher e consequentemente a sua autoestima, contribuindo para sua submissão e dependência ao agressor.

A violência contra a mulher constitui grave ameaça à vida que não se limita à saúde da mulher, mas de toda a sociedade, com repercussão danosa na economia e no desenvolvimento saudável da população. É fundamental que os profissionais de saúde estejam sensibilizados e capacitados para identificar mulheres em situação de abuso físico e emocional; e, por conseguinte, providenciar a assistência e os encaminhamentos necessários, tanto para redes de atenção quanto de proteção social. As instituições precisam funcionar de maneira articulada, visando romper com o ciclo da violência da qual essas mulheres estão inseridas e com isso impedir que ocorram novos episódios. A notificação é apenas o primeiro passo para sua visibilidade, enfrentamento e superação.

\section{REFERÊNCIAS}

1. Minayo MCS. A inclusão da violência na agenda da saúde: trajetória histórica. Ciênc. Saúde Coletiva. 2006; 11(Supl):1259-67. http://dx.doi.org/10.1590/S1413-81232006000500015.

2. Krug EG, Dahlberg LL, Mercy JA, Zwi AB, Lozano R. Relatório mundial sobre violência e saúde [Internet]. Genebra: Organização Mundial da Saúde; 2002 [citado em 2017 Nov 14]. 351 p. Disponível em: https:// www.opas.org.br/wp-content/uploads/2015/09/relatorio-mundial-violencia-saude.pdf

3. Organização das Nações Unidas para a Eduação, a Ciência e a Cultura. Declaração Universal dos Direitos Humanos: adotada e proclamada pela resolução 217 A (III) da Assembleia Geral das Nações Unidas em 10 de dezembro de 1948 [Internet]. Brasília: UNESCO; 1998 [citado em 2017 Nov 14]. 6 p. Disponível em: http://unesdoc.unesco.org/images/0013/001394/139423por.pdf

4. Barsted LL. Os Direitos Humanos na perspectiva de gênero [Internet]. São Paulo; 2001 [citado em 2017 Nov 14]. 9 p.Disponível em: http://www.dhnet.org.br/direitos/textos/a_pdf/barsted_dh_perspectiva_genero.pdf

5. Brasil. Casa Civil. Lei no 11.340, de 7 de agosto de 2006. Cria mecanismos para coibir a violência doméstica e familiar contra a mulher, nos termos do § $8^{\circ}$ do art. 226 da Constituição Federal, da Convenção sobre a Eliminação de Todas as Formas de Discriminação contra as Mulheres e da Convenção Interamericana para Prevenir, Punir e Erradicar a Violência contra a Mulher; dispõe sobre a criação dos Juizados de Violência Doméstica e Familiar contra a Mulher; altera o Código de Processo Penal, o Código Penal e a Lei de Execução Penal; e dá outras providências. Diário Oficial da União [Internet], Brasília, 8 de agosto de 2006 [citado em 2017 Dez 12]. Disponível em: http://www.planalto.gov.br/ccivil_03/_ato2004-2006/2006/lei/ I11340.htm

6. Brasil. Lei federal $n^{\circ} 10.886$, de 17 de junho de 2004. Acrescenta parágrafos ao artigo 129 do DecretoLei 2.848 de 7 de dezembro de 1940 do Código Penal, criando o tipo especial denominado "Violência Doméstica". Diário Oficial da União [Internet], Brasília, 18 de junho de 2004; Seção 1, p. 11.

7. Brasil. Lei federal no 10.778 , de 24 de novembro de 2003. Estabelece a notificação compulsória, no território nacional, do caso de violência contra a mulher que for atendida em serviços de saúde públicos ou privados. Diário Oficial da União [Internet], Brasília, 25 de novembro de 2003; Seção 1, p. 11.

8. Brasil. Ministério da Saúde. Secretaria de Vigilância em Saúde. Departamento de Vigilância de Doenças e Agravos Não Transmissíveis e Promoção da Saúde. Viva: Vigilância de Violências e Acidentes 2013 e 2014. Brasília: Ministério da Saúde; 2017. 
9. Brasil. Ministério da Saúde. Portaria n 104, de 25 de janeiro de 2011. Define as terminologias adotadas em legislação nacional, conforme disposto no Regulamento Sanitário Internacional 2005 (RSI 2005), a relação de doenças, agravos e eventos em saúde pública de notificação compulsória em todo o território nacional e estabelecer fluxo, critérios, responsabilidades e atribuições aos profissionais e serviços de saúde. Diário Oficial da União [Internet], Brasília, 26 de janeiro de 2011; Seção 1, p. 37.

10. World Health Organization. Global and regional estimates of violence against women: prevalence and health effects of intimate partner violence and non-partner sexual violence [Internet]. Geneva:WHO; 2013 [citado em 2017 Jan 21]. Disponível em: http://apps.who.int/iris/bitstream/10665/85239/1/9789241564625_eng.pdf

11. Schraiber LB, D'Oliveira AFPL, Couto MT, Hanada H, Kiss LB, Durand JG, et al. Violência contra mulheres entre usuárias de serviços públicos de saúde da Grande São Paulo. Rev Saude Publica. 2007;41(3):359-67. http://dx.doi.org/10.1590/S0034-89102007000300006. PMid:17515988.

12. Brasil. Ministério da Saúde. Secretaria de Vigilância em Saúde. Departamento de Vigilância de Doenças e Agravos não Transmissíveis e Promoção da Saúde. Notificação de violências interpessoais e autoprovocadas. Brasília: Ministério da Saúde; 2017.

13. Silva LEL, Oliveira MLC. Características epidemiológicas da violência contra a mulher no Distrito Federal, 2009 a 2012. Epidemiol Serv Saude. 2016;25(2):331-42. PMid:27869951.

14. Andrade JO, Castro SS, Heitor SFD, Andrade WP, Atihe CC. Indicadores da violência contra a mulher provenientes das notificações dos serviços de saúde de Minas Gerais - Brasil. Texto Contexto Enferm. 2016;25(3):1-9.

15. Delziovo CR, Bolsoni CC, Nazário NO, Coelho EBS. Características dos casos de violência sexual contra mulheres adolescentes e adultas notificadas pelos serviços públicos de saúde em Santa Catarina, Brasil. Cad Saude Publica. 2017;33(6):e00002716. http://dx.doi.org/10.1590/0102-311x00002716. PMid:28724022.

16. Instituto Brasileiro de Geografia e Estatítica [Internet]. 2017 [citado em 2017 Nov 21]. Disponível em: https://ww2.ibge.gov.br/home/estatistica/populacao/estimativa2017/estimativa_dou.shtm

17. São Paulo. Secretaria Municipal de Saúde [Internet]. 2017 [citado em 2017 Dez 15]. Disponível em: http://tabnet.saude.prefeitura.sp.gov.br/cgi/deftohtm3.exe?secretarias/saude/TABNET/SIVVA/agressao/ AGRESSAO.DEF

18. Marinheiro AL, Vieira EM, de Souza L. Prevalência da violência contra a mulher usuária de serviço de saúde. Rev Saude Publica. 2006;40(4):604-10. http://dx.doi.org/10.1590/S0034-89102006000500008. PMid:16906310.

19. Osis MJ, Duarte GA, Faúndes A. Violência entre usuárias de unidades de saúde: prevalência, perspectiva e conduta de gestores e profissionais. Rev Saude Publica. 2012 abr;46(2):351-8. http://dx.doi.org/10.1590/ S0034-89102012005000019. PMid:22358072.

20. Leite FMC, Amorim MHC, Wehrmeister FC, Gigante DP. Violência contra a mulher em Vitória, Espírito Santo. Rev Saude Publica. 2017 abr;51:33. PMid:28423136.

21. Kind L, Orsini MLP, Nepomuceno V, Gonçalves L, Souza GA, Ferreira MFF. Subnotificação e (in)visibilidade da violência contra mulheres na atenção primária à saúde. Cad Saude Publica. 2013;29(9):1805-15. http:// dx.doi.org/10.1590/S0102-311X2013001300020. PMid:24068226.

22. Galleguillos TGB, Neves H, Lira MMTA, Nazário C, Castro I, Freitas M, et al. Aspectos da questão étnicoracial e saúde no Município de São Paulo [Internet]. Boletim CElnfo Análise. 2015;10(12):60. [citado em 2018 Jan 10]. Disponível em: https://pesquisa.bvsalud.org/portal/resource/pt/lil-773753

23. Venturi G, Godinho T. Mulheres Brasileiras e Gênero Nos Espaços Público e Privado - uma década de mudanças na opinião pública. São Paulo: Fundação Perseu Abramo, Edições Sesc; 2013.

24. Araújo MF. Gênero e violência contra a mulher: o perigoso jogo de poder e dominação [Internet]. Psicol. Am. Lat. 2008;14 [citado em 2018 Jan 10]. Disponível em: http://pepsic.bvsalud.org/scielo.php?script=sci_ arttext\&pid=S1870-350X2008000300012

25. Costa MS, Serafim MLF, Nascimento ARS. Violência contra a mulher: descrição das denúncias em um Centro de Referência de Atendimento à Mulher de Cajazeiras, Paraíba, 2010 a 2012. Epidemiol Serv Saude. 2015;24(3):551-8. http://dx.doi.org/10.5123/S1679-49742015000300022.

26. Barufaldi LA, Souto RMCV, Correia RSB, Montenegro MMS, Pinto IV, Silva MMA, et al. Violência de gênero: comparação da mortalidade por agressão em mulheres com e sem notificação prévia de violência. Cien Saude Colet. 2017;22(9):2929-38. http://dx.doi.org/10.1590/1413-81232017229.12712017.PMid:28954144.

27. Deslandes SF, Gomes R, Silva CMFP. Caracterização dos casos de violência doméstica contra a mulher atendidos em dois hospitais públicos do Rio de Janeiro. Cad Saude Publica. 2000;16(1):129-37. http:// dx.doi.org/10.1590/S0102-311X2000000100013. PMid:10738157.

28. Mattos PR, Ribeiro IS, Camargo VC. Análise dos casos notificados de violência contra mulher. Cogitare Enferm. 2012;17(4):738-44. http://dx.doi.org/10.5380/ce.v17i4.30383. 